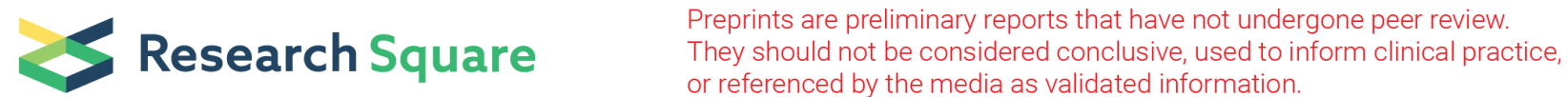

\section{Apolipoprotein C3 and Necrotic Core Volume Are Correlated but Also Associated With Future Cardiovascular Events}

Takayuki Ohwada ( $\square$ ikyoku18@fukushima-med-jrc.jp )

Fukushima Red Cross Hospital

\section{Takayuki Sakamoto}

Fukushima Red Cross Hospital

Satoshi Suzuki

Takeda General Hospital

Yukiko Sugawara

Fukushima Medical University

Kazuhiko Nakazato

Fukushima Medical University

Yasuchika Takeishi

Fukushima Medical University

Kenichi Watanabe

Fukushima Red Cross Hospital

Kazuya Sakamoto

Fukushima Red Cross Hospital

Ayano Ikeda

Fukushima Medical University

Fumika Haga

Fukushima Red Cross Hospital

\section{Research Article}

Keywords: Apolipoprotein, Necrotic Core, Cardiovascular Events

Posted Date: January 3rd, 2022

DOI: https://doi.org/10.21203/rs.3.rs-1202085/v1

License: (c) (i) This work is licensed under a Creative Commons Attribution 4.0 International License.

Read Full License 


\section{Abstract}

We aimed to clarify the relationship between apolipoprotein C3 (apo-C3) and vascular composition of lesion plaque in stable coronary disease (SCD) before percutaneous coronary intervention (PCI) and to investigate major adverse cardiovascular events (MACEs) within 4 years. Data of 98 consecutive patients with SCD who underwent PCI between November 1, 2012, and March 10, 2015, were analyzed. Laboratory evaluation and virtual histology-intravascular ultrasound (VH-IVUS) examination of culprit lesions were conducted before PCl. Patients were divided according to the median apo-C3 value into low apo-C3 ( $\leq 8.5$ $\mathrm{mg} / \mathrm{dL})$ and high apo-C3 $(>8.5 \mathrm{mg} / \mathrm{dL})$ groups. VH-IVUS data indicated that the percentage of necrotic core volume (\%NC) was significantly higher in the high apo-C3 group than in the low apo-C3 group. Moreover, the \%NC significantly correlated with the apo-C3 level $(R=0.2109, P=0.037)$. Kaplan-Meier curve analysis revealed that freedom from MACEs decreased more in the high apo-C3 group than in the low apo-C3 group and in the high \%NC group than in the low \%NC group. Multivariate Cox hazards analysis showed that the \% NC and high apo-C3 were independent predictors of 4-year MACEs. Apo-C3 may be a useful marker for future MACEs in patients with SCD after $\mathrm{PCl}$ and contribute to \% NC growth.

\section{Introduction}

In a meta-analysis ${ }^{[1]}$ and several studies ${ }^{[2,3]}$ that have investigated the plaque volume and vessel composition using virtual histology-intravascular ultrasound (VH-IVUS) during percutaneous coronary intervention $\left(\mathrm{PCl}\right.$ ) before and after taking statins, statins reduced the plaque volume ${ }^{[4]}$ and percentage of necrotic core volume (\%NC). Previously, we showed the correlation of the $\% \mathrm{NC}$ with apolipoprotein $\mathrm{B}$ and low-density lipoprotein $(L D L)$ cholesterol ${ }^{[5]}$. These effects are presumed to be partly due to the lowering of LDL cholesterol. However, previous reports ${ }^{[6,7]}$ have shown that the cholesterol-lowering effect of strong statins on major adverse cardiovascular events (MACEs) was only $24 \%$ when compared with that of placebo. Thus, LDL cholesterol may not be the only factor that affects plaque volume and vessel composition.

Apolipoprotein C3 (apo-C3) is associated with triglyceride-rich lipoprotein metabolism and has emerged as an independent marker of the risk for cardiovascular disease (CVD) ${ }^{[8-13]}$. Apo-C3 concentrations in chylomicron-free serum were reported to be associated with event-free survival in patients with coronary artery disease ${ }^{[13]}$. Nonetheless, thus far, the relationship between apo-C3 and vessel composition has not been clarified. In particular, NC is a key feature of vulnerable plaque ${ }^{[14]}$, and MACEs associated with NC have not been investigated.

Therefore, in this study, we conducted VH-IVUS before PCl to examine the vessel structure and to evaluate the relationship between apo-C3 and vessel composition. We also analyzed the Kaplan-Meier curves for MACEs associated with apo-C3 or the \%NC in the plaque in patients with stable coronary disease (SCD) after PCl. 


\section{Results}

\section{Comparisons of clinical characteristics, laboratory data, and IVUS data between high and low apo-C3 groups}

During the follow-up period of 48 months, 26 MACEs occurred (one cardiac death, two acute myocardial infarctions, five unstable anginas, 12 new progressive lesions requiring $\mathrm{PCl}$, three restenoses of the $\mathrm{PCl}$ site that required repeated $\mathrm{PCl}$, two arteriosclerosis obliterans requiring endovascular therapy, and one cerebral infarction). Patients were divided according to the median apo-C3 value into low apo-C3 ( $\leq 8.5$ $\mathrm{mg} / \mathrm{dL})$ and high apo-C3 (>8.5 mg/dL) groups (Tables 1-3). Comparisons of clinical characteristics and oral medication between the groups are presented in Table 1 . The body mass index was higher in the high apo-C3 group than in the low apo-C3 group. 
Table 1

Comparisons of clinical characteristics and oral medications between the low and high apo-C3 groups

\begin{tabular}{|c|c|c|c|}
\hline & $\begin{array}{l}\text { Low apo-C3 group ( } \leq 8.5 \mathrm{mg} / \mathrm{dL} \text {, } \\
\mathrm{n}=52 \text { ) }\end{array}$ & $\begin{array}{l}\text { High apo-C3 group (>8.5 mg/dL, } \\
\mathrm{n}=46 \text { ) }\end{array}$ & $\begin{array}{l}\mathrm{P}- \\
\text { value }\end{array}$ \\
\hline Age (years) & $67.9 \pm 1.2$ & $71.5 \pm 1.4$ & 0.0533 \\
\hline $\begin{array}{l}\text { Male patients, no. } \\
(\%)\end{array}$ & $40(76.9)$ & $34(73.9)$ & 0.7295 \\
\hline BMI & $23.8 \pm 0.5$ & $25.7 \pm 0.5$ & $0.001 *$ \\
\hline \multicolumn{4}{|l|}{ Clinical history } \\
\hline DM & $15(28.8)$ & $17(37.0)$ & 0.3929 \\
\hline Hypertension & $34(65.4)$ & $38(82.6)$ & 0.0539 \\
\hline Family history & $6(11.5)$ & $9(19.6)$ & 0.2707 \\
\hline Smoking & $15(28.8)$ & $17(37.0)$ & 0.3929 \\
\hline Previous PCl & $23(44.2)$ & $15(32.6)$ & 0.2386 \\
\hline Previous MI & $9(17.3)$ & $7(15.2)$ & 0.7799 \\
\hline \multicolumn{4}{|l|}{ Oral medications } \\
\hline $\mathrm{CCB}$ & $24(46.2)$ & $25(54.3)$ & 0.4181 \\
\hline ACEI/ARB & $25(48.1)$ & $21(45.7)$ & 0.8103 \\
\hline Antiplatelet drugs & $38(73.1)$ & $31(67.4)$ & 0.5383 \\
\hline Anti-DM drugs & $9(17.3)$ & $6(13.0)$ & 0.5585 \\
\hline Fibrates & $1(1.9)$ & $1(2.2)$ & 0.9302 \\
\hline Statin & $22(42.3)$ & $23(50.0)$ & 0.4457 \\
\hline \multicolumn{4}{|c|}{ Values are presented as means \pm standard errors or as numbers (percentages) of patients. } \\
\hline \multicolumn{4}{|l|}{$* P<0.05$} \\
\hline \multicolumn{4}{|c|}{$\begin{array}{l}\text { apo-C3, apolipoprotein C3; BMI, body mass index; DM, diabetes mellitus; } \mathrm{PCl} \text {, percutaneous coronary } \\
\text { intervention; MI, myocardial infarction; CCB, calcium-channel blocker; ACEI/ARB, angiotensin- } \\
\text { converting enzyme inhibitor/angiotensin II receptor blocker }\end{array}$} \\
\hline
\end{tabular}


Table 3

Comparisons of gray-scale IVUS, VH-IVUS data, and MACEs between the low and high apo-C3 groups Low apo-C3 group $(\leq 8.5 \mathrm{mg} / \mathrm{dL}$, $\mathrm{n}=52$ ) $\mathrm{n}=46$ )

Gray-scale data

Vessel volume

$789.0 \pm 87.9$

$806.9 \pm 66.1$

0.8731

$\left(\mathrm{mm}^{3}\right)$

Plaque volume

$480.2 \pm 35.4$

$316.7 \pm 27.1$

0.8868

$\left(\mathrm{mm}^{3}\right)$

Lumen volume

$308.8 \pm 54.3$

$480.2 \pm 54.3$

0.8633

$\left(\mathrm{mm}^{3}\right)$

\%Plaque burden

(\%)

$60.9 \pm 0.9$

$61.1 \pm 1.3$

0.8655

Length ( $\mathrm{mm}$ )

$54.8 \pm 0.9$

$55.6 \pm 0.8$

0.5658

VH-IVUS data

FI volume

$179.7 \pm 23.1$

$182.3 \pm 18.9$

0.9321

FF volume

$84.5 \pm 12.6$

$65.4 \pm 6.9$

0.2028

$\mathrm{NC}$ volume

$48.2 \pm 5.9$

$58.9 \pm 8.3$

0.2884

DC volume

$15.8 \pm 1.5$

$19.1 \pm 2.4$

0.2328

$\% \mathrm{FI}$

$54.8 \pm 0.9$

$55.6 \pm 0.8$

0.5658

\%FF

$24.1 \pm 1.2$

$20.5 \pm 1.0$

$<0.68^{*}$

$\% \mathrm{NC}$

$14.9 \pm 0.6$

$17.5 \pm 0.8$

$0.0143^{*}$

$\% \mathrm{DC}$

$6.1 \pm 0.5$

$6.5 \pm 0.5$

0.5982

MACES

Total MACE (\%) $7(13.5)$

19 (41.3)

$0.0018^{*}$

AMI (\%)

1 (1.9)

1 (2.2)

0.9302

UAP (\%)

$3(5.8)$

2 (4.3)

0.7496

Cardiac death (\%) $\quad 0(0)$

$1(2.2)$

0.2852

apo-C3, apolipoprotein C3; IVUS, intravascular ultrasound; VH-IVUS, virtual histology-intravascular ultrasound; Fl, fibrous; FF, fibrofatty; NC, necrotic core; DC, dense calcium; \%FI, percentage of the FI volume in the plaque volume; \%FF, percentage of the $\mathrm{FF}$ volume in the plaque volume; $\% \mathrm{NC}$, percentage of the $\mathrm{NC}$ volume in the plaque volume; \%DC, percentage of the $\mathrm{DC}$ volume in the plaque volume; MACE, major cardiovascular event (defined in the manuscript); AMI, acute myocardial infarction; UAP, unstable angina pectoris; EVT, endovascular therapy; Cl, cerebral infarction. 


\begin{tabular}{|c|c|c|c|}
\hline & $\begin{array}{l}\text { Low apo-C3 group ( } \leq 8.5 \mathrm{mg} / \mathrm{dL} \text {, } \\
\mathrm{n}=52 \text { ) }\end{array}$ & $\begin{array}{l}\text { High apo-C3 group (>8.5 mg/dL, } \\
\mathrm{n}=46 \text { ) }\end{array}$ & P-value \\
\hline Restenosis (\%) & $1(1.9)$ & $3(6.5)$ & 0.2509 \\
\hline New lesion (\%) & $2(3.8)$ & $10(21.7)$ & $0.0070 *$ \\
\hline EVT (\%) & $0(0)$ & $2(4.3)$ & 0.1287 \\
\hline $\mathrm{Cl}(\%)$ & $0(0)$ & $1(2.2)$ & 0.2852 \\
\hline \multicolumn{4}{|c|}{$\begin{array}{l}\text { apo-C3, apolipoprotein C3; IVUS, intravascular ultrasound; VH-IVUS, virtual histology-intravascular } \\
\text { ultrasound; FI, fibrous; FF, fibrofatty; NC, necrotic core; DC, dense calcium; \%FI, percentage of the FI } \\
\text { volume in the plaque volume; \%FF, percentage of the FF volume in the plaque volume; \%NC, } \\
\text { percentage of the NC volume in the plaque volume; \%DC, percentage of the DC volume in the plaque } \\
\text { volume; MACE, major cardiovascular event (defined in the manuscript); AMI, acute myocardial } \\
\text { infarction; UAP, unstable angina pectoris; EVT, endovascular therapy; Cl, cerebral infarction. }\end{array}$} \\
\hline
\end{tabular}

The levels of total cholesterol (TC), triglycerides (TG), non-high-density lipoprotein cholesterol (HDL-C), apo-A1, apo-B, and apo-C3 were higher in the high apo-C3 group than in the low apo-C3 group (Table 2). The LDL-C levels were lower in the high apo-C3 group than in the low apo-C3 group. Figure 1A shows the coronary angiography (CAG) findings in a representative case (a male patient in the high apo-C3 group, with an apo-C3 level of $8.8 \mathrm{mg} / \mathrm{dL}$ at enrollment) and VH-IVUS findings of the lesion. The intra- $(r=0.98$ and 0.99$)$ and inter-observer ( $r=0.96$ and 0.98$)$ measurement variability was acceptable. CAG images revealed an intermediate lesion in the proximal right coronary artery (Fig. 1A a). Drug-eluting stents were implanted in the target severe stenotic tandem lesion in the left mid-circumflex coronary artery (mid-CX) (Fig. 1A b-d). The patient received statin treatment due to hyperlipidemia. The LDL-C level was $55 \mathrm{mg} / \mathrm{dL}$ 8 months later, and at that time, the patient had an acute myocardial infarction in the mid-right coronary artery (Fig. 1A e). The stenting left CX site showed no restenosis (Fig. 1A f). Figure 1A g (cross-sectional image) and $\mathrm{h}$ (longitudinal image) show the pre-PCI VH-IVUS findings of the target lesion of the mid-CX, which revealed thin-cap fibroatheroma with NC (red region) and dense calcium (DC) (white region). The $\% \mathrm{NC}$ was $22.43 \%$. 
Table 2

Comparisons of laboratory data between the low and high apo-C3 groups
Low apo-C3 group ( $\leq 8.5 \mathrm{mg} / \mathrm{dL}$,
$\mathrm{n}=52$ )
High apo-C3 group $(>8.5 \mathrm{mg} / \mathrm{dL}$, $\mathrm{n}=46$ )

\begin{tabular}{llll}
\hline Laboratory data & & $206 \pm 6.0$ & $<0.001^{*}$ \\
\hline TC $(\mathrm{mg} / \mathrm{dL})$ & $174.8 \pm 4.1$ & $210.6 \pm 12.8$ & $<0.0011^{*}$ \\
\hline $\mathrm{TG}(\mathrm{mg} / \mathrm{dL})$ & $117.7 \pm 6.4$ & $55.0 \pm 1.9$ & 0.4122 \\
\hline $\mathrm{HDL}-\mathrm{C}(\mathrm{mg} / \mathrm{dL})$ & $52.9 \pm 1.7$ & $151.2 \pm 6.2$ & $<0.001^{*}$ \\
\hline $\begin{array}{l}\text { non-HDL-C } \\
(\mathrm{mg} / \mathrm{dL})\end{array}$ & $121.9 \pm 4.0$ & $94.9 \pm 5.8$ & $0.0304^{*}$ \\
\hline LDL-C $(\mathrm{mg} / \mathrm{dL})$ & $109 \pm 3.3$ & $138.4 \pm 2.7$ & $0.0107^{*}$ \\
\hline Apo-A1 $(\mathrm{mg} / \mathrm{dL})$ & $128.4 \pm 2.7$ & $102.6 \pm 3.9$ & $<0.001^{*}$ \\
\hline Apo-B $(\mathrm{mg} / \mathrm{dL})$ & $83.8 \pm 2.3$ & $12.3 \pm 0.50$ & $<0.001^{*}$ \\
\hline Apo-C3 $(\mathrm{mg} / \mathrm{dL})$ & $7.0 \pm 0.15$ & $6.3 \pm 0.183$ & $<0.92$ \\
\hline HbA1c $(\%)$ & $5.9 \pm 0.101$ & $0.348 \pm 0.071$ & $<0.58$ \\
\hline Hs-CRP $(\mathrm{mg} / \mathrm{dL})$ & $0.154 \pm 0.051$ & &
\end{tabular}

Values are presented as means \pm standard errors or as numbers (percentages) of patients. ${ }^{*} P<0.05$.

apo-C3, apolipoprotein C3; TC, total cholesterol; TG, triglyceride; HDL-C, high-density lipoprotein cholesterol; LDL-C, low-density lipoprotein cholesterol; HbA1c, hemoglobin A1c; hs-CRP, highsensitivity C-reactive protein.

Comparisons of gray-scale IVUS, VH-IVUS data, and MACEs between the low and high apo-C3 groups are presented in Table 3.

Gray-scale IVUS data, including \%plaque burden, were all comparable between the low and high apo-C3 groups. Regarding VH-IVUS data, the percentage of the fibrofatty (FF) volume in the plaque volume (\%FF) was significantly lower in the high apo-C3 group than in the low apo-C3 group. Meanwhile, the \%NC volume was significantly higher in the high apo-C3 group than in the low apo-C3 group. Total MACE and the incidence of new lesions were significantly higher in the high apo-C3 group than in the low apo-C3 group.

\section{Correlations between apo-C3 levels and four vessel compositions}

Furthermore, we investigated the correlations between apo-C3 levels and four vessel compositions evaluated by VH-IVUS. Only the \%NC among the four compositions significantly correlated with the apoC3 level ( $R=0.2109, P=0.037)$ (Fig. 1B). Moreover, we evaluated the correlations of the four vessel compositions with each other. The percentage of the fibrous $(\mathrm{FI})$ volume in the plaque volume $(\% \mathrm{FI})$ 
significantly inversely correlated with the \%FF $(R=-0.4628, P<0.001)$ and percentage of the $D C$ volume in the plaque volume $(\% \mathrm{DC})(\mathrm{R}=-0.5343, \mathrm{P}<0.001)$. The \%FF significantly inversely correlated with the \%NC $(R=-0.7520, P<0.001)$ and \%DC $(R=-0.3868, P<0.001)$. The \%NC significantly positively correlated with the $\% \mathrm{DC}(\mathrm{R}=0.5991, \mathrm{P}<0.001)$.

\section{Kaplan-Meier curves for comparisons between patients with high apo-C3 and those with low apo-C3}

Kaplan-Meier curves (Fig. 1C) revealed that patients with apo-C3 levels $>8.5 \mathrm{mg} / \mathrm{dL}$ (high apo-C3; $\mathrm{n}=46$ ) had significantly lower freedom from MACEs than those with apo-C3 levels $\leq 8.5 \mathrm{mg} / \mathrm{dL}$ (low apo-C3; $\mathrm{n}=52)(\mathrm{P}=0.0026)$. The mean survival time with high apo-C3 was $33.3 \pm 2.7$ (95\% confidence interval [Cl] 28.0-38.6) months, while that with low apo-C3 was $44.4 \pm 1.4(95 \% \mathrm{Cl} 41.7-47.1)$ months. Interestingly, patients with high \%NC (>median value $=16.675 \%$ ) of the lesion plaque showed significantly lower freedom from MACEs than those with low $\% \mathrm{NC}$ ( $\leq$ median value=16.675\%) of the lesion plaque (Fig. 1D). The mean survival time with high \%NC was $35.6 \pm 2.5(95 \% \mathrm{Cl} 30.6-40.5)$ months, while that with low $\% \mathrm{NC}$ was $42.8 \pm 1.8(95 \% \mathrm{Cl} 39.2-46.3)$ months.

\section{Cox proportional hazards regression model for 4-year MACES}

In the univariate analysis, the \%NC (hazard ratio [HR], 1.1207; 95\% $\mathrm{Cl} 1.0337-1.2151 ; \mathrm{P}=0.0057$ ), \%DC (HR, 1.1454; 95\% Cl 1.0482-1.2581; $\mathrm{P}=0.0046)$, and high apo-C3 (HR, 3.4977; 95\% Cl 1.4696-8.3258; $\mathrm{P}=00047$ ) were significant risk factors for 4-year MACEs. Moreover, the multivariate analysis showed that the \%NC (HR, 1.0960; 95\% Cl 1.0099-1.1894; $\mathrm{P}=0.028)$ and high apo-C3 (HR, 2.9381; 95\% Cl: $1.2106-$ 7.0820; $\mathrm{P}=0.0171$ ) were strong predictors of 4-year MACEs (Table 4). 
Table 4

Univariate and multivariate Cox hazards analyses for predicting 4-year MACEs

\begin{tabular}{|c|c|c|c|c|c|c|}
\hline Variable & $\begin{array}{l}\text { Unadjusted } \\
\text { HR }\end{array}$ & $95 \% \mathrm{Cl}$ & P-value & $\begin{array}{l}\text { Adjusted } \\
\text { HR }\end{array}$ & $95 \% \mathrm{Cl}$ & P-value \\
\hline Male sex & 2.0606 & $\begin{array}{l}0.7092- \\
5.9871\end{array}$ & 0.1840 & & & \\
\hline BMI & 1.0813 & $\begin{array}{l}0.9826- \\
1.1900\end{array}$ & 0.1095 & & & \\
\hline Smoking & 0.5491 & $\begin{array}{l}0.2205- \\
1.3674\end{array}$ & 0.1978 & & & \\
\hline Statin & 1.9332 & $\begin{array}{l}0.8871- \\
4.2128\end{array}$ & 0.0972 & & & \\
\hline HDL-C & 1.0190 & $\begin{array}{l}0.9906- \\
1.0481\end{array}$ & 0.1914 & & & \\
\hline LDL-C & 0.9889 & $\begin{array}{l}0.9760- \\
1.0020\end{array}$ & 0.0974 & & & \\
\hline Apo-B & 1.0111 & $\begin{array}{l}0.9960- \\
1.0262\end{array}$ & 0.1509 & & & \\
\hline Apo-C3 & 1.0758 & $\begin{array}{l}0.9691- \\
1.1943\end{array}$ & 0.1704 & & & \\
\hline$\% \mathrm{FI}$ & 0.9581 & $\begin{array}{l}0.9028- \\
1.0166\end{array}$ & 0.1571 & & & \\
\hline$\% \mathrm{FF}$ & 0.9509 & $\begin{array}{l}0.8962- \\
1.0089\end{array}$ & 0.0955 & & & \\
\hline$\% \mathrm{NC}$ & 1.1207 & $\begin{array}{l}1.0337- \\
1.2151\end{array}$ & $0.0057 *$ & 1.0960 & $\begin{array}{l}1.0099- \\
1.1894\end{array}$ & 0.0280 * \\
\hline$\% \mathrm{DC}$ & 1.1454 & $\begin{array}{l}1.0482- \\
1.2581\end{array}$ & $0.0046^{*}$ & & & \\
\hline $\begin{array}{l}\text { High apo- } \\
\text { C3 }\end{array}$ & 3.4977 & $\begin{array}{l}1.4696- \\
8.3258\end{array}$ & $0.0047^{*}$ & 2.9381 & $\begin{array}{l}1.2106- \\
7.0820\end{array}$ & $0.0171 *$ \\
\hline \multicolumn{7}{|c|}{$\begin{array}{l}\text { apo-C3, apolipoprotein } \mathrm{C} 3 \text {; MACE, major cardiovascular event; } \mathrm{HR} \text {, hazard ratio; } \mathrm{Cl} \text {, confidence interval; } \\
\text { BMI, body mass index; HDL-C, high-density lipoprotein cholesterol; LDL-C, low-density lipoprotein } \\
\text { cholesterol; \%FI, percentage of the FI volume in the plaque volume; \%FF, percentage of the FF volume } \\
\text { in the plaque volume; \%NC, percentage of the NC volume in the plaque volume; \%DC, percentage of } \\
\text { the DC volume in the plaque volume; high apo-C3, patients with apo-C3 }>8.5 \mathrm{mg} / \mathrm{dL} \text {. }\end{array}$} \\
\hline
\end{tabular}

\section{Discussion}

In this study, we clarified the relationship between apo-C3 and vessel composition in patients with SCD who underwent $\mathrm{PCl}$. The \%NC in the lesion plaque was higher in the high apo-C3 group than in the low apo-C3 group. Interestingly, the \%NC significantly correlated with apo-C3. Moreover, the overall survival 
rate from MACEs was significantly lower in the high apo-C3 group than in the low apo-C3 group. Additionally, the overall survival rate from MACEs was significantly lower in the high \%NC group than in the low \%NC group. Furthermore, Cox hazards analysis proved that a high apo-C3 level and the \%NC were independent predictors of 4-year MACEs. Our findings provide insights into the prognostic effect of apo$\mathrm{C} 3$ and the \%NC in the vessel components of patients with SCD after $\mathrm{PCl}$, and the relationship between these factors was correlated. Therefore, apo-C3 may induce NC volume development and could be a useful predictor of MACEs after PCl in patients with SCD. To the best of our knowledge, this is the first study to show the contribution of the \%NC to long-term MACEs in patients with SCD after PCI and the first study to demonstrate the correlation between apo-C3 and the \%NC.

Apo-C3, an important regulator of lipoprotein metabolism, is strongly associated with hypertriglyceridemia and CVD progression. In addition to its effects on lipid metabolism, apo-C3 directly influences atherosclerosis development through several routes, such as facilitating the subendothelial accumulation of LDLs by increasing their affinity for artery wall proteoglycans ${ }^{[15-18]}$. The mechanism underlying this interaction is complex because apo-C3 does not bind to artery wall proteoglycans but appears to provoke changes in the lipid composition of lipoproteins, causing apo-B to adopt a conformation more favorable for proteoglycan binding ${ }^{[15,16]}$. Apo-C3 may also promote the aggregation and fusion of retained lipoproteins in the artery wall by activating sphingomyelinases ${ }^{[19,20]}$. Furthermore, apo-C3 facilitates the interaction between monocytes and endothelial cells, promotes smooth muscle cell proliferation, and induces inflammation by activating adhesion molecules and proinflammatory nuclear factor-KB in monocytes and endothelial cells ${ }^{[21,22]}$.

To date, several reports ${ }^{[8-13]}$ have indicated that a high apo-C3 level is a predictor of future cardiovascular and ischemic cerebrovascular events in patients with CVD. Katzman et al. ${ }^{[13]}$ showed that apo-C3 concentrations in chylomicron-free serum were independently associated with event-free survival in patients with coronary artery disease in both fasting and postprandial states. However, patients in that study did not undergo $\mathrm{PCl}$, and the authors did not look at vascular composition. In a study conducted by Sacks et al. ${ }^{[10]}$, patients experienced a recent myocardial infarction but did not undergo PCI. In their study, Scheffer et al. ${ }^{[9]}$ included Caucasian patients and excluded patients with type 2 diabetes mellitus who did not necessarily have coronary artery disease. In any case, previous studies have not always included all PCI patients. In our study, the significantly more common type of MACE was the occurrence of new lesions. In this sense, the presence or absence of $\mathrm{PCl}$ may not be relevant to the results; however, we are the first to demonstrate that higher apo-C3 is worse in the prognosis of PCl patients. In addition, no previous studies have examined the relationship between apo-C3 and vascular structure.

Apo-C3 did not affect the gray-scale IVUS data (e.g., vessel volume and \%plaque burden) but altered the proportion of the composition of blood vessels. Apo-C3 decreased the \%FF and increased the \%NC. The NC may be formed with a matrix-devoid gruel of lipids and cell debris absorbed by macrophages and dendritic cells in the intima in a process that remains incompletely understood in vivo ${ }^{[14]}$. A close interplay among dendritic cells and other immune cells results in full-blown immune activation, paving 
the way for a detrimental rupture of the atherosclerotic plaque ${ }^{[23]}$. A larger NC also confers a greater risk than a small NC ${ }^{[14,24]}$. In our study, patients with high \%NC had a worse prognosis than those with low $\% \mathrm{NC}$. Furthermore, the \%NC was an independent predictor of 4-year MACEs after PCl in patients with SCD. Additionally, we have shown a significant positive correlation between apo-C3 and \%NC values, which suggests that apo-C3 influences the development of the \%NC. To the best of our knowledge, these results have not been reported before.

Since the \%NC cannot be assessed without VH-IVUS, which is an invasive method, it may be possible to predict future myocardial infarction if apo-C3, which can be assessed by blood sampling, is checked regularly as a surrogate marker in the outpatient clinic.

\section{Study limitations}

This study has some limitations. First, this was a single-center study with a small sample size; therefore, large-scale multicenter studies are needed to confirm our findings. However, with the advent of highresolution IVUS, VH-IVUS is only used for clinical research purposes, making it more difficult to conduct a study since it is used less frequently. Second, because of the small sample size, we could not examine additional confounding factors for apo-C3 (e.g., LDL-C and apo-B). Finally, most of the new lesions were discovered on repeated CAG 8 months after PCl. Nowadays, it is difficult to obtain informed consent to perform CAG 8 months after PCI However, in routine clinical practice, new lesions cannot be traced.

In conclusion, apo-C3 facilitates NC progression in the coronary arteries of patients with SCD and increases the risk of future cardiovascular events. Apo-C3 may be a potent surrogate marker for predicting future cardiovascular events in patients with SCD after PCI. Apo-C3 levels should be monitored periodically in outpatient medical examinations. If apo-C3 level is high, closer examination using coronary computed tomography, stress test, or CAG should be performed for monitoring of CVD progression.

\section{Methods}

This study was approved by the Ethics Committee of Fukushima Red Cross Hospital (Fukushima City, Japan; approval no. 2012-2) and performed in accordance with Ethical Guidelines for Clinical Research of the Japanese Ministry of Health, Labour and Welfare. Informed consent was obtained from all individual participants included in the study.

\section{Study population}

Our sample included a total of 98 consecutive patients with SCD who visited our hospital between November 1, 2012, and March 10, 2015, and underwent PCI with VH-IVUS. PCI was indicated in accordance with the Japanese consensus criteria ${ }^{[25]}$. After obtaining written informed consent, $\mathrm{PCl}$ and pre-IVUS were performed. All 98 patients were enrolled in this study, all of whom underwent coronary 
artery stenting in the target vessels. The degree of coronary stenosis was determined, and IVUS measurements were assessed by two investigators (TO and TS).

\section{IVUS image acquisition}

IVUS examinations of the culprit lesions were conducted immediately before PCl. A phased-array, 20-MHz, 3.2-F IVUS catheter (Eagle Eye; Volcano Corp., Rancho Cordova, CA, USA) was placed in the distal coronary artery and pulled back to the aorto-ostial junction using a motorized catheter pull-back system set at $0.5 \mathrm{~mm} / \mathrm{s}$ (Eagle Eye; Volcano Corp.). The gray-scale IVUS and captured radiofrequency data were recorded by a DVD recorder.

\section{Gray-scale and VH-IVUS analyses}

Offline gray-scale and VH-IVUS analyses were conducted using echo Plaque 4.0 software (INDEC Systems Inc., Los Altos, CA, USA). Corresponding proximal and distal reference IVUS images were identified for each culprit lesion and analyzed to determine the plaque volume within the involved arterial segment. Gray-scale IVUS analysis was conducted using the American College of Cardiology Clinical Expert Consensus Document on Standards for Acquisition, Measurement, and Reporting of Intravascular Ultrasound Studies ${ }^{[26]}$. In the gray-scale conventional IVUS analysis, images were assessed to determine the lesion length, lumen volume, plaque volume, and vessel volume. In the VH-IVUS analysis, the FI, FF, NC, and DC regions were color coded. Estimates of each factor's contribution to the volume of the entire culprit lesion plaque volume were reported as a percentage of the factor's volume in the plaque volume of the culprit lesion (i.e., NC) [27]. The same investigators (TO and TS) subsequently reanalyzed the images with respect to the intra- and inter-observer reproducibility of the measurements.

\section{Clinical laboratory measurements}

Laboratory evaluations of plasma lipid and apo levels were conducted within 2 days before PCl. Commercial reagent kits (Determiner L TC II, L LDL-C II, L HDL-C II, and L TG II; Kyowa Medex, Tokyo, Japan) were used to analyze total plasma cholesterol, LDL-C, HDL-C, and TG levels. Lipid concentrations were measured using an automated biochemical analyzer (Labospect 006; Hitachi, Tokyo, Japan). ApoC3 was measured in chylomicron-free samples, and apo-B and apo-A1 were measured using immunonephelometry. High-sensitivity C-reactive protein levels were measured using nephelometry. Apo levels were measured at a central clinical biochemistry laboratory (SRL Inc., Tokyo, Japan).

\section{Definition of 4-year MACEs}

MACEs within 4 years (48 months) were defined as a composite of cardiac death, acute myocardial infarction, unstable angina, coronary revascularization for restenosis of a target vessel and new lesion, endovascular therapy for arteriosclerosis obliterans, and cerebral infarction. These events were ascertained by reviewing patients' medical records and confirmed by direct dialog with patients, their families, and their physicians after discharge. If no events were experienced in about 8 months after PCl, the patients underwent repeated CAG. For $>90 \%$ stenosis in a target vessel (i.e., restenosis) or a new lesion, patients underwent revascularization using PCl; these events constituted MACEs. 


\section{Statistical analyses}

Data are presented as means \pm standard errors. Categorical and continuous variables of clinical characteristics were compared between the low and high apo-C3 groups, which were divided by the median apo-C3 value. Categorical data were analyzed using the chi-square test, and continuous data using Student's $t$-test. All statistical analyses were two-sided. The significance level was set at $P<0.05$. The comparisons of gray-scale IVUS, VH-IVUS data, and MACEs between the low and high apo-C3 groups were performed in the same manner.

Pearson's correlations between apo-C3 and the percentage of the four vessel compositions in the plaque (i.e., \%FI, \%FF, \%NC, and \%DC) were evaluated. Correlations among these four compositions were also evaluated. Kaplan-Meier curve analysis was conducted, and the 48-month MACE-free survival was compared between the low and high apo-C3 groups, which were divided by the median apo-C3 value, using the log-rank test, and between the low and high \%NC groups, which were divided by the median $\%$ NC value, using Wilcoxon test.

A Cox proportional hazards regression model was used to estimate the long-term MACE HR and 95\% Cls based on the univariate analysis of clinical, laboratory, and IVUS data and multivariate analysis of high apo-C3 levels adjusted for potential confounders (i.e., factors with $\mathrm{P}<0.05$ in the univariate analysis).

All statistical analyses were performed using Ekuseru-Toukei for Windows version 1.02 (SSRI Co., Ltd., Tokyo, Japan).

\section{Declarations}

\section{Availability of Data and Material}

All data generated or analyzed during this study are included in this published article.

\section{Acknowledgments}

This research did not receive any specific grant from funding agencies in the public, commercial, or notfor-profit sectors. The authors gratefully acknowledge the expertise of the staff members of our catheterization laboratory, especially Toshimi Kobayashi, Yoko Sato, Akemi Hagiwara, Noriko Kohata, Naoko Morita, Miyuki Konno, Murakami Futa, Shiozawa Shota, Aya Nakayama, Michiko Hayasaka, and Kenichi Hashimoto, as well as the staff of the catheterization laboratory at Fukushima Red Cross Hospital. We also thank Editage (www.editage.com) for their writing support.

\section{Author Contributions}

TO: conceptualization, data curation, methodology, formal analysis, investigation, and writing - original draft. TS: data curation and investigation. SS: writing - review and editing. YS: data acquisition. KS: data acquisition. Al: data acquisition. FH: data acquisition. KN: supervision, writing - review, and editing. YT: 
conceptualization, supervision, writing - review, and editing. KW: conception of the work. All authors read and approved the final manuscript.

\section{Competing Interests}

The authors declare no competing interests.

\section{References}

1 Tian, J. et al. Effect of statin therapy on the progression of coronary atherosclerosis. BMC Cardiovasc. Disord. 12, 70 (2012).

2 Lee, S. W. et al. Virtual histology findings and effects of varying doses of atorvastatin on coronary plaque volume and composition in statin-naive patients: the VENUS study. Circ. J. 76, 26622672 (2012).

3 Park, S. J. et al. Effect of statin treatment on modifying plaque composition: A double-blind, randomized study. J. Am. Coll. Cardiol. 67, 1772-1783 (2016).

$4 \quad$ Watanabe, T. et al. A randomized controlled trial of eicosapentaenoic acid in patients with coronary heart disease on statins. J. Cardiol. 70, 537-544 (2017).

5 Ohwada, T. et al. Apolipoprotein B correlates with intra-plaque necrotic core volume in stable coronary artery disease. PLoS One. 14, e0212539 (2019).

6 Bosch, J. et al. Lowering cholesterol, blood pressure, or both to prevent cardiovascular events: Results of 8.7 years of follow-up of Heart Outcomes Evaluation Prevention (HOPE)-3 study participants. Eur. Heart J. 42, 2995-3007 (2021).

7 Yusuf, S. et al. Cholesterol lowering in intermediate-risk persons without cardiovascular disease. N. Engl. J. Med. 374, 2021-2031 (2016).

8 Wyler von Ballmoos, M. C., Haring, B. \& Sacks, F. M. The risk of cardiovascular events with increased apolipoprotein CIII: A systematic review and meta-analysis. J. Clin. Lipidol. 9, 498-510 (2015).

9 Scheffer, P. G. et al. Increased plasma apolipoprotein C-III concentration independently predicts cardiovascular mortality: the Hoorn study. Clin. Chem. 54, 1325-1330 (2008).

10 Sacks, F. M. et al. VLDL, apolipoproteins B, CIII, and E, and risk of recurrent coronary events in the Cholesterol and Recurrent Events (CARE) trial. Circulation. 102, 1886-1892 (2000).

11 Olivieri, O. et al. Apolipoprotein C-III predicts cardiovascular mortality in severe coronary artery disease and is associated with an enhanced plasma thrombin generation. J. Thromb. Haemost. 8, 463471 (2010). 
patients with elevated apolipoprotein CIII. Stroke. 51, 61-68 (2020).

13 Katzmann, J. L. et al. Apolipoprotein CIII predicts cardiovascular events in patients with coronary artery disease: a prospective observational study. Lipids Health Dis. 19, 116 (2020).

14 Virmani, R., Burke, A. P., Farb, A. \& Kolodgie, F. D. Pathology of the vulnerable plaque. J. Am. Coll. Cardiol. 47, C13-C18 (2006).

15 Olin-Lewis, K. ApoC-III content of apoB-containing lipoproteins is associated with binding to the vascular proteoglycan biglycan. J. Lipid Res. 43, 1969-1977 (2002).

16 Hiukka, A. et al. ApoCIII-enriched LDL in type 2 diabetes displays altered lipid composition, increased susceptibility for sphingomyelinase, and increased binding to biglycan. Diabetes. $\mathbf{5 8}, \mathbf{2 0 1 8 -}$ 2026 (2009).

17 Gustafsson, M. \& Borén, J. Mechanism of lipoprotein retention by the extracellular matrix. Curr. Opin. Lipidol. 15, 505-514 (2004).

18 Davidsson, P. et al. A proteomic study of the apolipoproteins in LDL subclasses in patients with the metabolic syndrome and type 2 diabetes. J. Lipid Res. 46, 1999-2006 (2005).

19 Schissel, S. L. et al. Secretory sphingomyelinase, a product of the acid sphingomyelinase gene, can hydrolyze atherogenic lipoproteins at neutral $\mathrm{pH}$. Implications for atherosclerotic lesion development. J. Biol. Chem. 273, 2738-2746 (1998).

20 Ruuth, M. et al. Susceptibility of low-density lipoprotein particles to aggregate depends on particle lipidome, is modifiable, and associates with future cardiovascular deaths. Eur. Heart J. 39, 25622573 (2018).

21 Kawakami, A. et al. Apolipoprotein CIIl-induced THP-1 cell adhesion to endothelial cells involves pertussis toxin-sensitive g protein- and protein kinase $\mathrm{C}$ alpha-mediated nuclear factorkappaB activation. Arterioscler. Thromb. Vasc. Biol. 27, 219-225 (2007).

22 Kawakami, A. et al. Apolipoprotein CIII induces expression of vascular cell adhesion molecule-1 in vascular endothelial cells and increases adhesion of monocytic cells. Circulation. 114, 681-687 (2006).

23 Niessner, A. \& Weyand, C. M. Dendritic cells in atherosclerotic disease. Clin. Immunol. 134, 25$32(2010)$.

24 Ohayon, J. et al. Necrotic core thickness and positive arterial remodeling index: Emergent biomechanical factors for evaluating the risk of plaque rupture. Am. J. Physiol. Heart Circ. Physiol. 295, H717-727 (2008). 
25 Fujiwara, $\mathrm{H}$., et al. Guidelines for elective percutaneous coronary intervention in patients with stable coronary artery disease (JCS 2011) published in 2012-digest version. Circ. J. 77, 1590-1607 (2013).

26 Mintz, G. S. et al. American College of Cardiology Clinical Expert Consensus

Document on Standards for Acquisition, Measurement and Reporting of Intravascular Ultrasound Studies (IVUS). A Report of the American College of Cardiology Task Force on Clinical Expert Consensus Documents. J. Am. Coll. Cardiol. 37, 1478-1492 (2001).

27 Muramatsu, T. et al. Reproducibility of intravascular ultrasound radiofrequency data analysis (virtual histology) with a $45-\mathrm{MHZ}$ rotational imaging catheter in ex vivo human coronary arteries. $\mathrm{J}$. Cardiol. 65, 134-142 (2015).

\section{Figures}



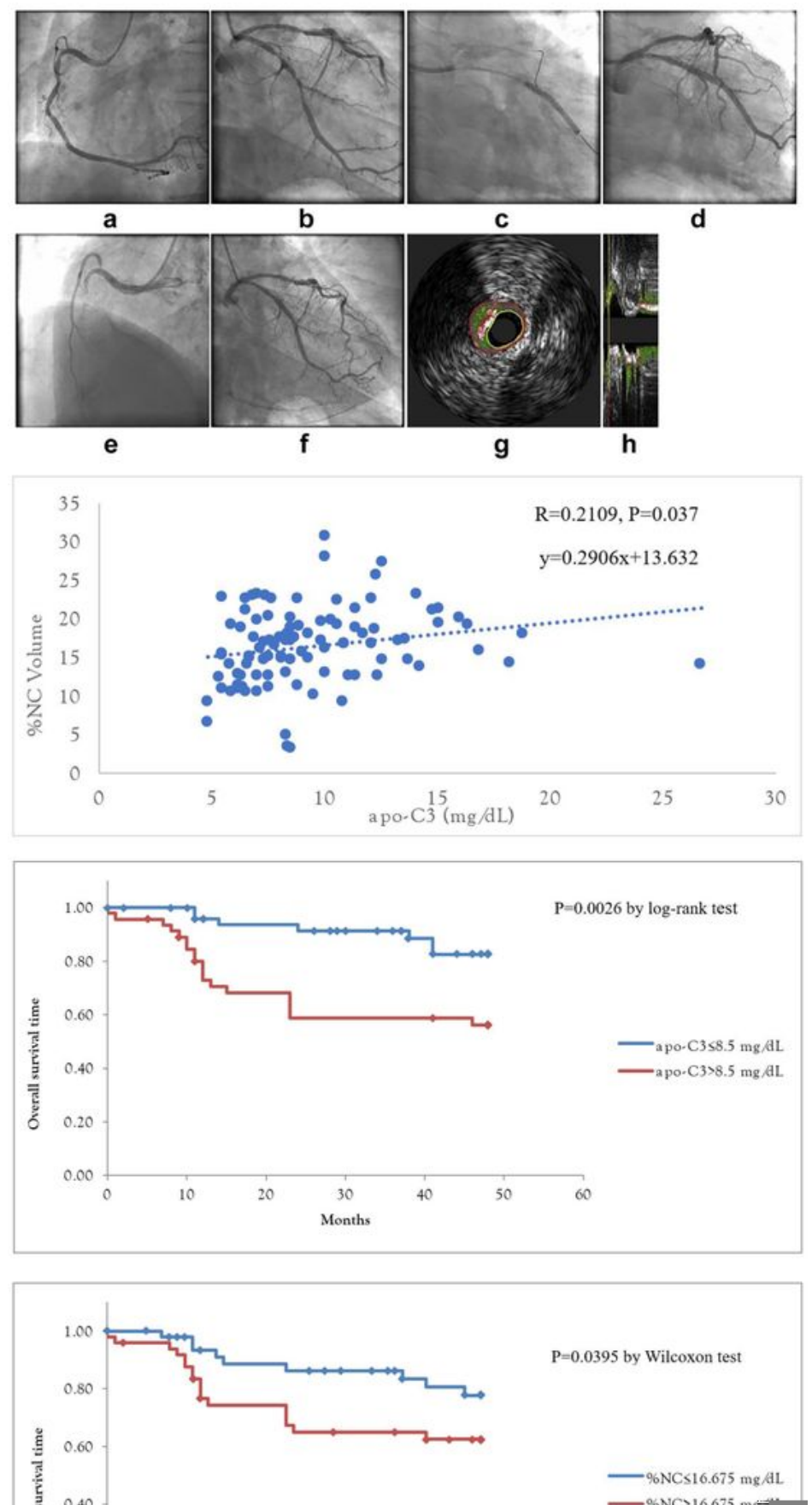

Figure 1

Representative case in the high apo-C3 group

1A Coronary angiograms of a representative case (a male patient) and virtual histology-intravascular ultrasound (VH-IVUS) of the lesion. (a) An intermediate lesion in the proximal right coronary artery at prepercutaneous coronary intervention (PCl). (b) The target severe stenotic tandem lesion in the left 
circumflex coronary artery (LCX). (c) Two drug-eluting stents were implanted. (d) Coronary angiography findings after stenting. (e, f) Eight months later, the patient experienced acute myocardial infarction and was transported to our hospital by ambulance; coronary angiography was immediately performed. (e) The mid-right coronary artery, which had an intermediate lesion before $\mathrm{PCl}$, was completely occluded. (f) The LCX showed no restenosis. (g) The VH-IVUS cross-sectional image of the lesion that underwent PCI in the LCX. (h) The longitudinal VH-IVUS image of the same lesion. In the color image, green indicates the fibrous region; yellowish green, the fibrofatty region; red, the necrotic core; and white, dense calcium. In this patient, the percentage necrotic core volume was $22.43 \%$, and the apolipoprotein C3 level was $8.8 \mathrm{mg} / \mathrm{dL}$.

1B Correlation curve between apo-C3 and \%NC volume. There was a significant correlation between apo$\mathrm{C} 3$ and $\%$ NC volume $(\mathrm{P}=0.037)$.

1C Kaplan-Meier curves between patients with high apo-C3 and those with low apo-C3. Kaplan-Meier curves indicated that patients with high apo-C3 levels $(>8.5 \mathrm{mg} / \mathrm{dL})$ had a significantly lower freedom from MACEs than those with lower apo-C3 levels $(\leq 8.5 \mathrm{mg} / \mathrm{dL})(P<0.001)$.

1D Kaplan-Meier curves between patients with high \%NC and those with low \%NC. Kaplan-Meier curves indicated that patients with high \%NC (>median value $=16.675 \%$ ) had significantly lower freedom from MACEs than did those with low \%NC ( $\leq$ median value $=16.675 \%)(P<0.001)$. 